\title{
Northern Hemisphere atmospheric pattern enhancing Eastern Mediterranean Transient-type events during the past 1000 years
}

\author{
Aleix Cortina-Guerra ${ }^{1}$, Juan José Gomez-Navarro ${ }^{2}$, Belen Martrat ${ }^{1}$, Juan Pedro Montávez ${ }^{2}$, Alessandro Incarbona ${ }^{3}$, \\ Joan O. Grimalt ${ }^{1}$, Marie-Alexandrine Sicre ${ }^{4}$, and P. Graham Mortyn ${ }^{5,6}$ \\ ${ }^{1}$ Department of Environmental Chemistry, Institute of Environmental Assessment and Water Research (IDAEA), \\ Spanish Council for Scientific Research (CSIC), Barcelona, Spain \\ ${ }^{2}$ Department of Physics, University of Murcia, Murcia, Spain \\ ${ }^{3}$ Dipartimento di Scienze della Terra e del Mare, Università di Palermo, Palermo, Italy \\ ${ }^{4}$ Sorbonne Universités (UPMC, Université Paris 06)-CNRS-IRD-MNHN, LOCEAN Laboratory, Paris, France \\ ${ }^{5}$ Institute of Environmental Science and Technology (ICTA), Universitat Autònoma de Barcelona, \\ Bellaterra, Barcelona, Spain \\ ${ }^{6}$ Department of Geography, Universitat Autònoma de Barcelona, Bellaterra, Barcelona, Spain
}

Correspondence: Aleix Cortina-Guerra (acortina@usal.es) and Joan O. Grimalt (joan.grimalt@idaea.csic.es)

Received: 5 March 2021 - Discussion started: 24 March 2021

Revised: 4 June 2021 - Accepted: 13 June 2021 - Published: 20 July 2021

\begin{abstract}
High-resolution climate model simulations for the last millennium were used to elucidate the main winter Northern Hemisphere atmospheric pattern during enhanced Eastern Mediterranean Transient (EMT-type) events, a situation in which an additional overturning cell is detected in the Mediterranean at the Aegean Sea. The differential upward heat flux between the Aegean Basin and the Gulf of Lion was taken as a proxy of EMT-type events and correlated with winter mean geopotential height at $500 \mathrm{mbar}$ in the Northern Hemisphere $\left(20-90^{\circ} \mathrm{N}\right.$ and $\left.100^{\circ} \mathrm{W}-80^{\circ} \mathrm{E}\right)$. Correlations revealed a pattern similar to the East Atlantic/Western Russian (EA/WR) mode as the main driver of EMT-type events, with the past 1000 years of EA/WR-like mode simulations being enhanced during insolation minima. Our model results are consistent with alkenone sea surface temperature (SST) reconstructions that documented an increase in the west-east basin gradients during EMT-type events.
\end{abstract}

\section{Introduction}

The Mediterranean Sea is a small, semi-enclosed basin connected with the Atlantic Ocean through the Strait of Gibral$\operatorname{tar}$ (a $284 \mathrm{~m}$ deep sill at a width of $\sim 30 \mathrm{~km}$; Bryden and Kinder, 1991). The Sicily channel (330 m deep sill, width of $\sim 130 \mathrm{~km}$; Wüst, 1961) subdivides the Mediterranean into a western and an eastern basin. An anti-estuarine pattern (Béthoux, 1979) characterizes the current Mediterranean general circulation, mainly driven by a negative water budget, involving the inflow of relatively fresh surface Atlantic waters and exit of relatively salty bottom Mediterranean waters (Fig. 1). The entering colder and fresher Atlantic Waters (AW) interact with the warmer and saltier Mediterranean waters, which constitutes the main surface water mass of the Mediterranean (0-200 m) (Malanotte-Rizzoli et al., 2014, and references therein). The AW is the source of Levantine Intermediate Water (LIW; 200-600 m), and both are involved in deep-water mass formation (Malanotte-Rizzoli et al., 2014). Northwesterly winds in the Adriatic Sea, where Eastern Mediterranean Deep Waters (EMDW) form, and in the Gulf of Lion, where Western Mediterranean Deep Water (WMDW) forms, are key elements for enhanced deep-water ventilation through deep convection (Millot, 1999).

An important perturbation in the Mediterranean overturning circulation took place in the late 1980 s to the mid1990s that involved the formation of an overturning cell in the Aegean Sea (see Fig. 1) (Roether et al., 1996). This episode was termed the Eastern Mediterranean Transient (EMT) event and involved major changes on the seawater physical and biogeochemical properties, including changes 


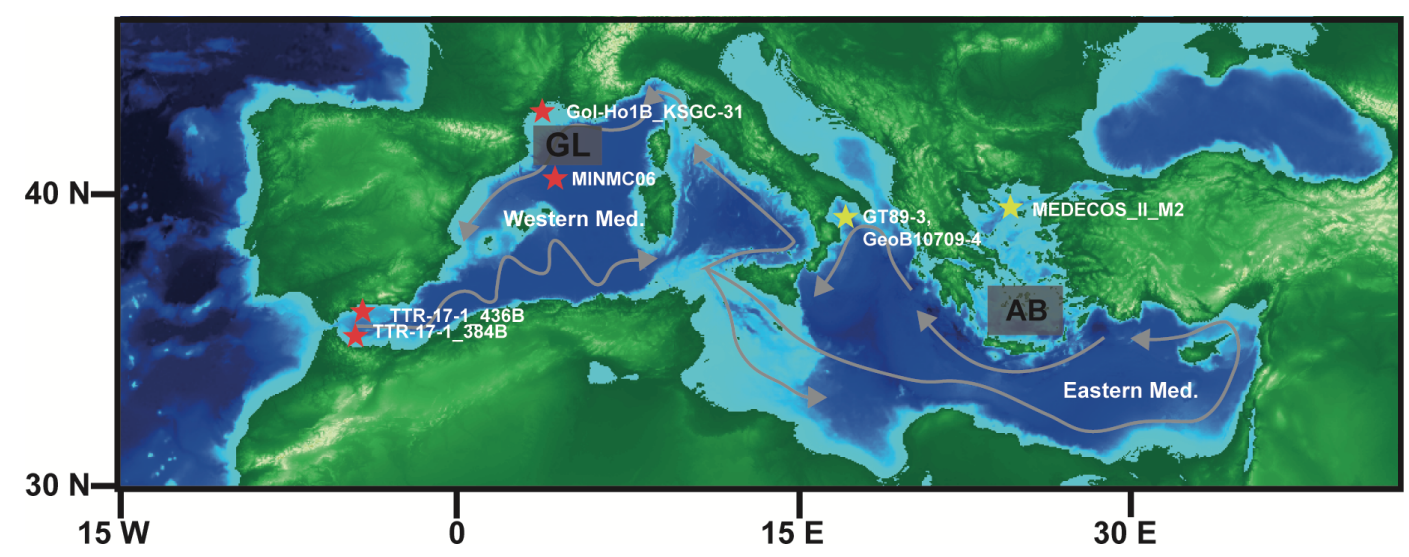

Figure 1. Map of the Mediterranean Sea modified after Incarbona et al. (2016). Grey arrows depict main surface water paths. Stars show the location of cores used to calculate the sea surface temperature (SST) gradient between western (red stars) and eastern (yellow stars) basins (W-E). Shaded rectangles show the area taken for estimation of the differential winter upward heat flux between the Aegean Basin and Gulf of Lion (AB-GL).

in the vertical and spatial distribution of anthropogenic carbon (Touratier and Goyet, 2011). Moreover, concurrent with the EMT event, a reduction of the mixed layer depth (MLD) and winter heat flux in the Gulf of Lion (Beuvier et al., 2010; Herrmann et al., 2010) was observed, indicating a weakening of deep-water formation in the western Mediterranean (Incarbona et al., 2016). Enhanced deep-water ventilation in the eastern Mediterranean associated with wintertime cold polar/continental air outbreaks (Rohling et al., 2019) has been related to sea surface salinity minima in the Sicily channel both in recent (Gasparini et al., 2005) and past EMT-type events (Incarbona et al., 2016).

It has been suggested that the origin of EMT-type events could be related to modifications in atmospheric patterns operating at global scale such as the North Atlantic Oscillation (NAO) or East Atlantic/Western Russia (EA/WR) modes, low solar irradiance together with increase of volcanic eruptions (Incarbona et al., 2016). However, a robust demonstration using past climate model simulations is still lacking. Here, results for the past 1000 years of highresolution $(45 \mathrm{~km})$ simulations carried out with a regional climate model (RCM) driven by a global circulation model (GCM) are presented. This approach provides insight into how changes in global atmospheric circulation patterns affect Mediterranean heat loss, which are closely related to deep-water formation rates (Sur et al., 1993; Josey, 2003; Herrmann et al., 2010). The present study, therefore, identifies past EMT-type events and defines the timing and the global atmospheric pattern of variability that enhanced them.

\section{Methods}

\subsection{Climate simulations}

A GCM and a nested RCM have been used to produce a consistent climate simulation of the European climate for the past 1000 years. The GCM is the ECHO-G model and consists of the spectral atmospheric model ECHAM4 coupled to the ocean model HOPE-G. This GCM setup has a spatial resolution of about $3.75^{\circ} \times 3.75^{\circ}$ in the atmosphere and $2.8^{\circ} \times 2.8^{\circ}$ in the ocean and has been employed and thoughtfully evaluated in the literature (Zorita et al., 2003). These data have been dynamically downscaled with a RCM based on a climate version of the Fifth-Generation Pennsylvania State University/National Center for Atmospheric Research mesoscale model (MM5). The model domain encompasses Europe and the Mediterranean region entirely and implements a spatial resolution of $45 \mathrm{~km}$. As with ECHO-G, this model setup has been evaluated elsewhere (Gómez-Navarro et al., 2013, 2015). Both models are consistently driven by reconstructions of three external forcings: greenhouse gas concentrations in the atmosphere, long-term variations in total solar irradiance (TSI) and variations of Earth's orbital parameters. The results of coupling the RCM with the GCM are hereafter referred to as MM5-ECHO-G.

Upward heat fluxes calculated within MM5-ECHO-G are used in this study as a predictor of deep-water formation. In this regard, it is important to note that MM5-ECHO-G does not include a high-resolution regional ocean model. Instead, sea surface temperature (SST) variations are directly taken from the driving GCM and imposed as an additional boundary condition to the RCM. Still, the latter calculates the heat fluxes between the atmosphere and the surface, including the prescribed ocean SST, according to meteorological conditions. Therefore, the heat fluxes within the RCM simulation are consistently obtained according to the large-scale atmospheric circulation prescribed by the GCM but improved according to the additional information provided by regional circulation features driven by the high-resolution orography and land mask of the RCM. Thus, a monthly upward heat flux evaluation is needed to identify times of year when en- 
hanced heat loss occurs. MM5-ECHO-G simulations for the past 1000 years showed that, on average, the SeptemberFebruary period (autumn-winter) (Fig. A1) accounted for most of the annual upward heat flux. Hence, the analysis is performed over this period, referred to as winter hereafter for convenience although it encompasses autumn months as well.

\subsection{Detection of the synoptic circulation pattern-related heat flux variability}

Our study is based on the hypothesis that EMT-type events are related to enhanced deep-water formation in the Aegean Sea with respect to the Gulf of Lion. In order to find the spatial pattern that most clearly influences deep-water formation in the Aegean Sea, we first define two boxes delimiting deepwater formation areas in the Mediterranean: (1) Gulf of Lion (GL) $\left(41.5-43^{\circ} \mathrm{N}, 3.5-6.5^{\circ} \mathrm{E}\right)$ and (2) Aegean Basin (AB) (35.7-37. $5^{\circ} \mathrm{N}, 23.5-27^{\circ} \mathrm{E}$ ) (Fig. 1). Winter upward heat flux difference between the $\mathrm{AB}$ and the GL is then calculated, so that positive values are associated with enhanced deep-water formation in the $\mathrm{AB}$, and conversely with respect to the GL. As the magnitude of the upward heat flux in both regions can be very different and we seek relative variations, both series were standardized before estimating the difference. Thereby, we obtain the following annual series:

$\Delta_{\mathrm{HF}}(t)=\mathrm{HF}_{\mathrm{AB}}(t)-\mathrm{HF}_{\mathrm{GL}}(t)$,

where $\Delta_{\mathrm{HF}}$ denotes the gradient of heat flux, and $\mathrm{HF}_{\mathrm{AB}}$ and $\mathrm{HF}_{\mathrm{GL}}$ the standardized heat fluxes averaged for the aforementioned boxes and September-February months. To find the spatial structure of atmospheric dynamic that most strongly affects the gradient of upward heat flux, the series (Eq. 1) is correlated with the winter mean geopotential height at 500 mbar (hereafter Z500) obtained from the driving GCM in the region $20-90^{\circ} \mathrm{N}$ and $100^{\circ} \mathrm{W}-80^{\circ} \mathrm{E}$ (Fig. 2):

$\rho(x)=\operatorname{cor}\left(\Delta_{\mathrm{HF}}(t), Z 500(x, t)\right)$.

This pattern can be interpreted as a mode where associated variability is most strongly associated with the differences in deep-water formation between the $\mathrm{AB}$ and the GL.

Mathematically, this correlation map can be treated as a vector and can be used to find an associated index by projecting the original Z500 field onto it. For this, the pattern has to be normalized first:

$\rho(x)=\frac{\rho(x)}{\sqrt{\rho(x) \cdot \rho(x)}}$,

where $\rho(x)$ represents the normalized vector and "." is the scalar product. Now, the index that represents the "weight" of this pattern throughout the last millennium, but optimized for the explanation of deep-water formation in the AB, is simply obtained as the projection of Z500 onto the pattern:

$I_{\text {nhp }}^{\prime}(t)=Z 500(x, t) \cdot(x)$.
The variance of $I^{\prime}{ }_{\text {nhp }}$ (nhp stands for Northern Hemisphere pattern) can be compared to the total variance of the original field of $Z 500$, which results in $11 \%$ of the variance of the whole field. A possible drawback of the index defined by (4) is that it is affected by changes in global temperature, as geopotential height is closely related to temperature through the hypsometric equation. This implies that this index responds simultaneously to changes in atmospheric circulation as well as in global temperature. In order to overcome this problem while keeping the signal of the atmospheric dynamics, the spatially averaged $Z 500$ is removed to define a new index:

$I_{\mathrm{nhp}}(t)=Z 500^{\prime}(x, t) \cdot \rho(x)$,

where $Z 500^{\prime}(x, t)=Z 500(x, t)-\langle Z 500(x, t)\rangle$ and " \langle\rangle " denotes spatial average.

Lastly, to complement this analysis and gain insight into the physical relationship between this circulation pattern and the variables that modulate heat flux at the surface, we perform composite analysis based on the $I_{\text {nhp }}$ index. This analysis is carried out filtering out situations according to the aforementioned index values. In particular, dates corresponding to values over the 90th percentile are selected, and the corresponding fields of the variable target of the analysis are averaged. This is repeated for the dates of the lower 10th percentile values, and finally both averages are subtracted, yielding a map of anomalies that represents the impact of the index variability on the given variable. The rationale for this approach is that under the null hypothesis of no relation whatsoever between the variability of the index to select dates and the variables, a composite is equivalent to a random selection of dates, which statistically cancels out after taking differences. And conversely, large deviations from zero, either positive or negative, are indicative of strong influence on the index on this variable.

\subsection{Calculating western/eastern sea surface temperature proxy}

In order to validate model simulations a western/eastern alkenone-based SST gradient was calculated. Western (W) (Moreno et al., 2012; Nieto-Moreno et al., 2013; Sicre et al., 2016) and eastern (E) (Versteegh et al., 2007; Grauel et al., 2013; Gogou et al., 2016) marine SST proxies were first standardized (Supplement), and average values of a period before, during and after solar minimum events (Crowley, 2000) of both basins were calculated in order to evaluate the evolution of $\mathrm{W}-\mathrm{E}$ gradients around solar minima (Table 1). The length of the period chosen to calculate average SST values was equal to the duration of solar minimum. 


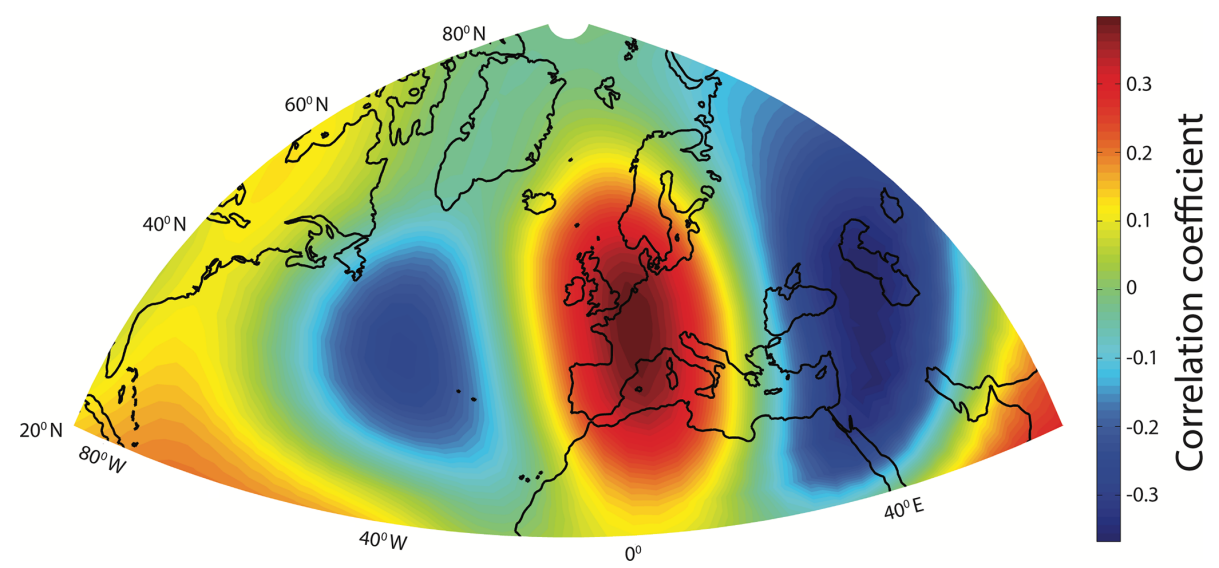

Figure 2. Correlation map between winter upward heat flux gradient (Aegean Basin versus Gulf of Lion difference) and winter mean geopotential height at 500 mbar $\left(Z 500^{\prime}\right)$. The map reveals the Northern Hemisphere atmospheric pattern most closely related to EMT-type events.

Table 1. Periods used to calculate western/eastern alkenone-based sea surface temperature (SST) gradient (W-E). Mean, standard deviation (SD) and number of cases $(n)$ are provided.

\begin{tabular}{lrrrrrrrr}
\hline Period & Mean W & SD W & $n \mathrm{~W}$ & Mean E & SD E & $n$ E & W-E & SD W-E \\
\hline $1920-1940$ & -0.15 & 0.51 & 4 & -0.18 & 0.83 & 15 & 0.03 & 0.78 \\
$1900-1920^{*}$ & -0.10 & 1.17 & 3 & -0.37 & 0.75 & 13 & 0.27 & 0.82 \\
$1880-1900$ & -0.15 & 1.00 & 5 & 0.19 & 0.64 & 15 & -0.34 & 0.73 \\
$1830-1870$ & -0.65 & 0.42 & 9 & -0.36 & 0.76 & 29 & -0.29 & 0.70 \\
$1790-1830^{*}$ & 0.06 & 0.98 & 7 & 0.15 & 0.75 & 22 & -0.08 & 0.80 \\
$1750-1790$ & -0.57 & 0.47 & 8 & 0.71 & 1.11 & 27 & -1.28 & 1.01 \\
$1715-1785$ & -0.72 & 0.51 & 14 & -0.02 & 1.09 & 46 & -0.71 & 0.99 \\
$1645-1715^{*}$ & -0.15 & 0.88 & 19 & -0.81 & 0.61 & 29 & 0.67 & 0.73 \\
$1575-1645$ & -0.36 & 0.69 & 15 & 0.15 & 1.01 & 23 & -0.51 & 0.90 \\
\hline
\end{tabular}

$*$ denotes periods corresponding to solar minima.

\section{Results and discussion}

\subsection{Identification of the Northern Hemisphere atmospheric pattern most closely related to EMT-type events}

The correlation coefficient between the AB-GL gradient and Z500' in the Northern Hemisphere (Fig. 2) reveals a pattern characterized by positive correlations located over Europe and flanked by negative correlations over the central North Atlantic and over Western Russia. This pattern is reminiscent of the EA/WR pattern defined by the NOAA Climate Prediction Center (CPC), although the latter is obtained through rotated principal component analysis (Barnston and Livezey, 1987) of the observed monthly mean $500 \mathrm{mbar}$ height anomaly field in the region $20-90^{\circ} \mathrm{N}$. The impacts on air-sea heat exchange of variability modes affecting the Mediterranean have been studied by Josey et al. (2011). To relate air-sea heat exchange, deep-water formation and atmospheric circulation, Josey et al. (2011) used a top-bottom approach consisting of decomposing atmospheric dynamics in their more prominent modes of variability and associated indices and then looking for relationships between such modes and surface heat flux release in the Mediterranean. The results of this analysis revealed that the EA/WR mode most likely plays a major role in the deep-water formation in the AB. In our study, we applied a different strategy by undertaking a bottom-up approach, where the phenomenon to explain, i.e., changes in the locations of deep-water formation in the Mediterranean, is used to find a pattern based on physical processes. This type of approach enables more flexibility, as it allows the associated index to be optimized to explain the fraction of the atmospheric variability that most directly affects the given phenomenon, hence maximizing the signal sought. Therefore, the fact that the pattern obtained through a completely different approach resembles the EA/WR structure reinforces the findings of Josey et al. (2011) and extends them over the longer temporal frame of the past 1000 years. Our results demonstrate that the index representing the "weight" of this correlation pattern through the last millennium, calculated in Eqs. (4) and (5) (i.e., $I_{\text {nhp }}$ ), can be used as a proxy of EA/WR-like variability. This variability is associ- 
ated with changes in the deep-water formation zones and, in particular, with the occurrence of EMT-type events.

\subsection{Heat loss in Mediterranean Sea during EMT-type events}

To gain insight into how the EA/WR variability mode is related to changes in heat exchange, we have obtained composites of various variables defined according to the $I_{\text {nhp }}$ index. To calculate the net heat exchange between sea and atmosphere, four components need be taken into consideration: (1) sensible heat flux, (2) latent heat flux, (3) longwave flux and (4) shortwave flux. Winter net heat exchange is dominated by latent heat flux and to a lesser extent by sensible heat flux (Josey, 2003). These two components are driven by the product of the wind speed and the sea-air humidity and the sea-air temperature gradient (Josey et al., 1999). Therefore, to unravel the driving mechanisms of sea surface heat loss associated with the EA/WR-like mode, it is necessary to consider anomalous wind speed and air temperature fields (the atmospheric humidity field tends to follow air temperature and it is neglected) (Josey et al., 2011).

The composites of winter $2 \mathrm{~m}$ air temperature (i.e., nearsurface air temperature), upward heat flux and $10 \mathrm{~m}$ wind speed, obtained using the $I_{\text {nhp }}$ index, are shown in Fig. 3 . The intensification of the spatial pattern described in the former section is associated with an increased western flux in the eastern Mediterranean, which favors the intensification of cold winds from the continental regions that, in turn, increase the upward heat flux in this region promoting deepwater formation. Conversely, the pattern tends to reduce this zonal flow over the western Mediterranean, which therefore reduces the heat flux exchange there. These changes are summarized in the heat anomaly pattern of the top panel of Fig. 3, which is associated with an increased gradient between the $\mathrm{AB}$ and GL. This can also be appreciated in the near-surface temperature pattern, with the warm (cold) anomaly in the western (eastern) Mediterranean driven by reduced (enhanced) zonal flow, and that agrees with the anomalies of heat exchange aforementioned. This pattern is due to the anomalous high-pressure system centered over the North Sea that results in cold northwesterly airflow over the eastern Mediterranean and Black Sea and a warmer southeasterly airflow in the western Mediterranean, generating a dipole in the heat exchange (Josey et al., 2011). Usually in the Mediterranean Sea, the Levantine basin is characterized by higher temperatures, and large differences in the evaporation-precipitation balance facilitate LIW formation (Millot, 1999). Considering near-surface air temperature varying in parallel with SST, the predominance of this mode of variability results in reducing or compensating the average temperature gradient in the Mediterranean.

\subsection{EA/WR-like pattern variability during the past 1000 years and its influence on Mediterranean climate}

Solar activity and last millennium EA/WR-like pattern variability $I_{\text {nhp }}$ are shown in Fig. 4a-b. After applying Eq. (5) to $I_{\text {nhp }}^{\prime}$, the global temperature signal, and thus the possible thermodynamic effect of solar forcing on the index, was removed. The residual signal is solely attributed to variations in the atmospheric circulation. When comparing the $I_{\mathrm{nhp}}$ variability with solar forcing (Crowley, 2000), a good correspondence is revealed for the analyzed interval. In particular, the Lomb periodogram (Fig. 4f) reveals significant peaks of both signals with $\mathrm{a} \sim 125$-year periodicity (frequency $=0.008 \mathrm{yr}^{-1}$ ). After applying a Gaussian filter to both signals (Fig. 4e), frequency $=0.008 \pm 0.001 \mathrm{yr}^{-1}$ (i.e., 110-140-year periodicity range), a strong relationship arises $(r=-0.83, p<0.001)$. Interestingly, a similar variability has been previously documented (Baumgartner et al., 1992; Patterson et al., 2004, 2005; Cortina and Herguera, 2014, among others), attributed to solar activity expressed as changes in the ${ }^{14} \mathrm{C}$ content of the atmosphere $\left(\Delta^{14} \mathrm{C}\right)(\mathrm{Nef}-$ tel et al., 1981; Sonett, 1984; Stuiver and Braziunas, 1993). Our analysis suggests that solar activity minima with approximately 125 -year periodicity are related to $I_{\text {nhp }}$ enhancement and the ensuing expression of EA/WR-like atmospheric patterns. The latter is related to generation of EMT-type events through the physical relationship described above. Our results are in line with previous interpretations of circulation perturbation in the Mediterranean by Incarbona et al. (2016), who related solar irradiance lows with enhancement of EMTtype events, but we restrict this relationship to a 125-year cycle. The length of the simulation (1000 years) could preclude detection of longer periodicities, and low resolution of the solar forcing proxy from year 1000 to 1700 (Crowley, 2000) could prevent evaluation of low periodicities such as the 88year Gleissberg cycle (Gleissberg and Schove, 1958). The high resolution of our $I_{\text {nhp }}$ index can detect, in addition to the EA/WR-like enhancement associated with the last EMT event (Fig. 4), the less intense atmospheric changes related to a possible EMT event during the 1970s (Beuvier et al., 2010).

Model simulations were also compared with oceanic proxy reconstructions during three singular periods of solar minima: (1) Maunder (1645-1715 years), (2) Dalton (1790 1830 years) and (3) Gleissberg (1900-1920 years) (Table 1) (Fig. 4c, d). Since EMT-type events co-occurred with freshening events in the Sicily channel (Incarbona et al., 2016), anomalous low $\delta^{18} \mathrm{O}$ seawater values in this region (Fig. 4d) should be contemporaneous with enhanced $I_{\text {nhp }}$ associated with EA/WR-like mode. This correspondence is precise during the Gleissberg and Dalton minima, and the 10-year lag observed between the freshening event and the end of Maunder minimum (i.e., $1715 \mathrm{CE}$ ) is within its own chronological uncertainty ( \pm 25 years; Incarbona et al., 2016). On the other 

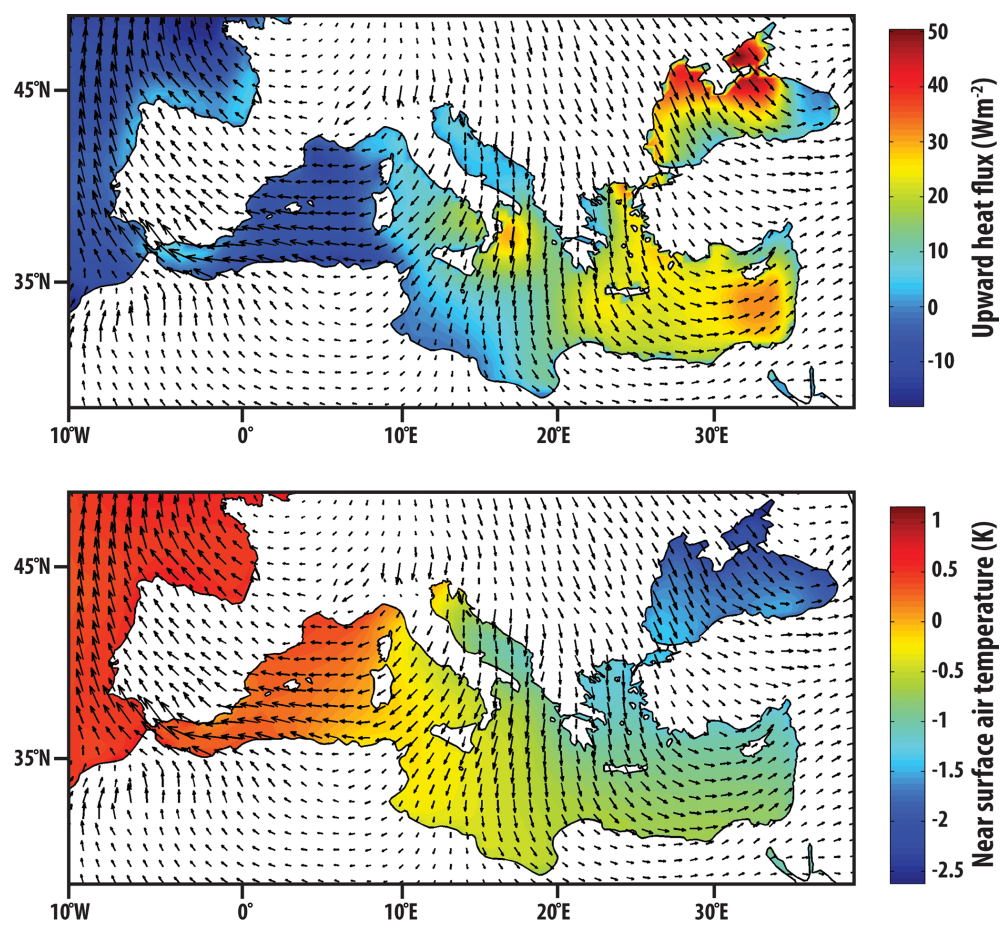

Figure 3. Mediterranean composite maps. Composite maps of winter near-surface air temperature ( $2 \mathrm{~m}$ ) and upward heat flux based on $I_{\text {nhp }}$ index. Dates corresponding to values over the 90th percentile are selected, and the corresponding fields of the variable target of the analysis are averaged. This is repeated for the dates of the lower 10th percentile values, and finally both averages are subtracted. Black arrows represent composite of $10 \mathrm{~m}$ wind speed direction and intensity.

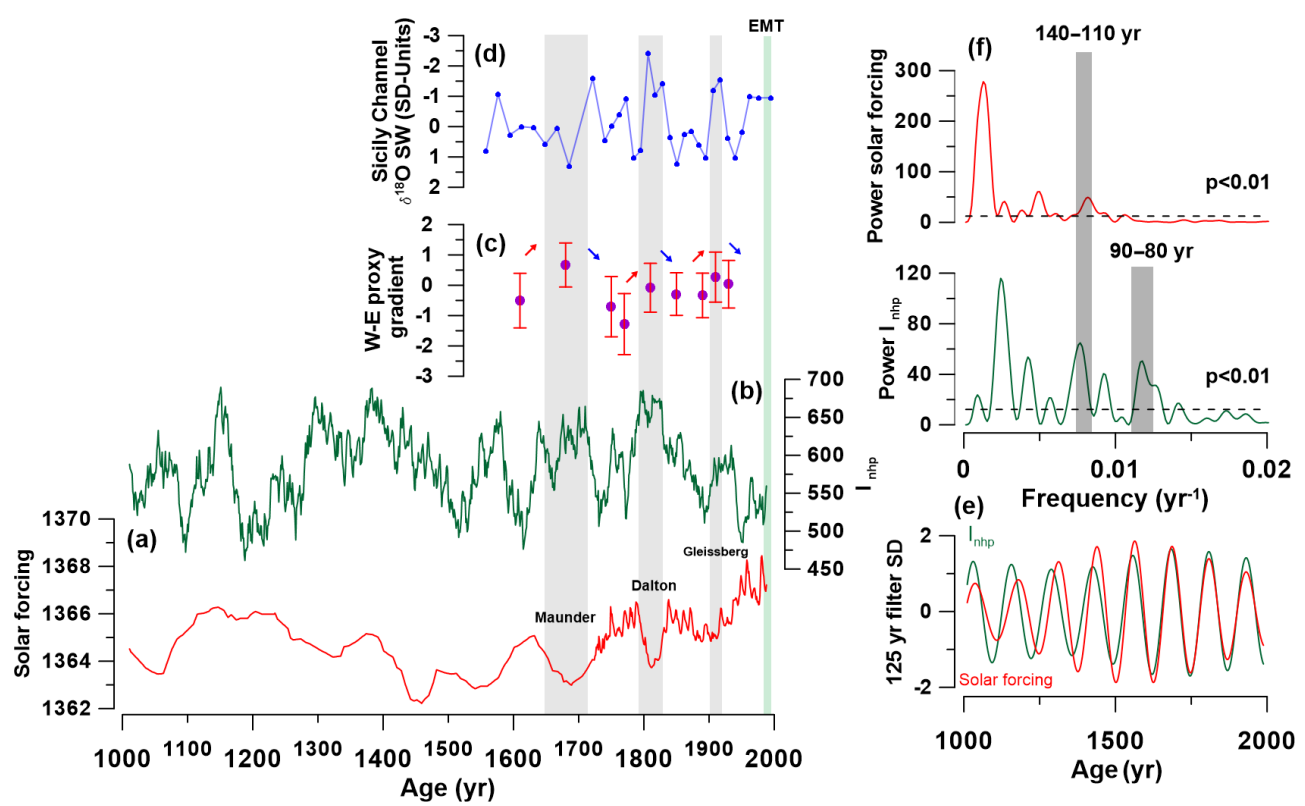

Figure 4. Past EA/WR-like pattern variability and its correspondence with climate proxies. (a) Solar forcing (Crowley, 2000). (b) $I_{\text {nhp }}$ index. (c) Western-eastern basin SST gradient. (d) Sicily channel $\delta^{18} \mathrm{O}$ sea water in standard units (Incarbona et al., 2016). (e) Standardized Gaussian filter centered at $0.008 \mathrm{yr}^{-1}$ (i.e., 125 years) with $0.001 \mathrm{yr}^{-1}$ bandwidth (i.e., $110-140$ years) of $I_{\text {nhp }}$ index and solar forcing. (f) Power spectra of solar forcing and $I_{\mathrm{nhp}}$ index based on Lomb periodogram algorithm using the PAST 3.12 software package (Hammer et al., 2001). Dashed lines represent white noise $(p<0.01)$. Grey bars at figures (a)-(d) represent periods of solar irradiance lows. Green bar in panels (a)-(d) refer to the last EMT event. 
hand, the near-surface temperature composite map revealed a reduced or compensated average temperature gradient between western and eastern Mediterranean basins during enhanced $I_{\text {nhp }}$ (EA/WR-like) pattern (Fig. 3). The W-E gradient derived from SST proxy reconstructions (Fig. 4c), which is independent of model simulations, agrees with these results, showing higher values (i.e., increased difference between western and eastern basin SSTs) during solar minima and an enhanced $I_{\text {nhp }}$ (EA/WR-like pattern).

The fact that the EA/WR-like mode dominated periods with increased differential upward heat flux between $A B$ and GL and increased W-E temperature gradient and hence the occurrence of EMT-type events does not exclude the influence of other important modes of atmospheric variability, such as positive phases of the North Atlantic Oscillation (NAO) (Incarbona et al., 2016). The EA/WR-like pattern explains about $11 \%$ of atmospheric variability in the simulation, whereas studies based on principal component analysis suggest that NAO accounts for about $40 \%$ of total variance (Jianping and Wang, 2003), demonstrating the strong influence of this mode on North Atlantic atmospheric circulation. However, our model simulation results discard a direct influence of positive NAO during periods with an increased upward heat flux gradient between $\mathrm{AB}$ and GL, restricting its impact most likely to atmospheric preconditioning.

\section{Conclusions}

The MM5-ECHO-G simulation can be used to characterize the global EA/WR-like atmospheric mode in the Mediterranean region, which favors continental cold winds to penetrate into the $\mathrm{AB}$, and blocks their influence in the GL. The model results assessed an increase in the winter upward heat flux gradient between the $\mathrm{AB}$ and GL and enhanced Mediterranean deep-water formation in the Aegean, with its impact on the circulation of the entire basin. At present, these oceanographic conditions have been related to the EMT event. Considering the same oceanographic conditions trigger past EMT-like events, our results show that during the past 1000 years, a dominant EA/WR-like mode and EMTtype events were contemporaneous with solar minima, likely related to cycles of approximately 125 and 80-90 years.

The model simulation is consistent with the multi-decadal return period of surface freshening in the Sicily channel, a proxy of EMT-type events, for the Maunder (16451715 years), (2) Dalton (1790-1830 years) and (3) Gleissberg (1900-1920 years) minima. Moreover, the simulation results are in line with alkenone-based SST proxies that document an increase of the W-E gradient during these periods as a consequence of wintertime northerly air outbreaks over the $\mathrm{AB}$. 


\section{Appendix A}
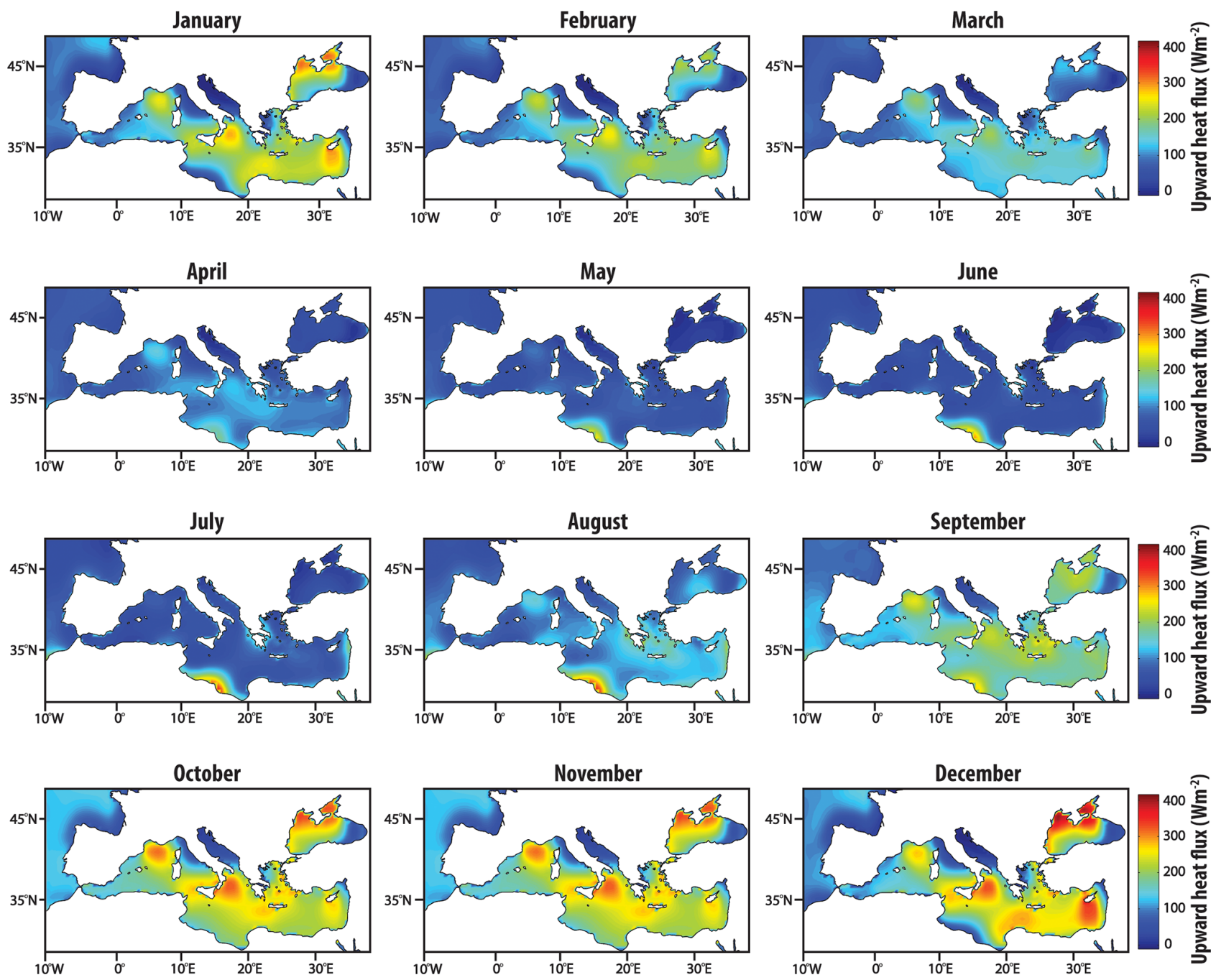

Figure A1. Monthly upward heat flux for MM5-ECHO-G paleosimulations for the last 1000 years identify September-February interval (autumn-winter) as the period contributing to most of the annual upward heat flux. Air-sea exchanges during this winter-centered half of the year span the main period for deep-water formation. In this study, for convenience this period is referred to as winter (although it contains the outlying months of September and October, which lie outside of a typical winter). 
Code availability. The methodology used is detailed in Sect. 2. No programming language has been used.

Data availability. Data are available in the Supplement.

Supplement. The supplement related to this article is available online at: https://doi.org/10.5194/cp-17-1523-2021-supplement.

Author contributions. ACG and JJGN developed the methodology, performed the format analysis and prepared the original draft. JPM and JOG reviewed and edited the manuscript. BM participated in the funding acquisition and conceptualization. AI, MAS and PGM participated in the conceptualization.

Competing interests. The authors declare that they have no conflict of interest.

Disclaimer. Publisher's note: Copernicus Publications remains neutral with regard to jurisdictional claims in published maps and institutional affiliations.

Acknowledgements. This work started as a collaboration between researchers with the PALEOLINK project by the PAGES $2 \mathrm{k}$ Network. We acknowledge support from the PAGES (Past Global Changes) $2 \mathrm{k}$ Network, funded by the US and Swiss National Science Foundations (NSF) and NOAA. We want also to acknowledge project PGC2018-102288-B-I00 funded by Ministerio de Ciencia, Innovación y Universidades. Juan José Gomez-Navarro acknowledges the funding obtained through the "Juan de la CiervaIncorporación” program (IJCI-2015-26914).

Financial support. This research has been supported by the Ministerio de Ciencia, Innovación y Universidades (grant no. PGC2018-102288-B-I00).

We acknowledge support of the publication fee by the CSIC Open Access Publication Support Initiative through its Unit of Information Resources for Research (URICI).

Review statement. This paper was edited by Hans Linderholm and reviewed by two anonymous referees.

\section{References}

Barnston, A. G. and Livezey, R. E.: Classification, seasonality and persistence of low-frequency atmospheric circulation patterns, Mon. Weather Rev., 115, 1083-1126, 1987.

Baumgartner, T., Soutar, A., and Ferreira-Bartrina, V.: Reconstruction of the history of pacific sardine and northern anchovy popu- lations over the past two millenia from sediments of the Santa Barbara Basin, California, Calif. Coop. Ocean. Fish. Investig. Reports, 33, 24-40, 1992.

Béthoux, J. P.: Budgets of the Mediterranean Sea - their dependence on the local climate and on the characteristics of the Atlantic waters, Oceanol. Acta 2, 157-163, 1979.

Beuvier, J., Sevault, F., Herrmann, M., Kontoyiannis, H., Ludwig, W., Rixen, M., Stanev, E., Béranger, K., and Somot, S.: Modeling the Mediterranean Sea interannual variability during 1961-2000: Focus on the Eastern Mediterranean Transient, J. Geophys. Res., 115, C08017, https://doi.org/10.1029/2009JC005950, 2010.

Bryden, H. L. and Kinder, T. H.: Steady two-layer exchange through the Strait of Gibraltar, Deep Sea Research Part A, 38, S445S463, https://doi.org/10.1016/S0198-0149(12)80020-3, 1991.

Cortina, A. and Herguera, J. C.: Mid-to-Late Holocene organic carbon export variability at the southern boundary of the California Current: An approach based on diffuse spectral reflectance of marine sediment cores, Palaeogeogr. Palaeocl., 408, 1-10. https://doi.org/10.1016/j.palaeo.2014.04.015, 2014.

Crowley, T. J.: Causes of climate change over the past 1000 years, Science, 289, 270-277, 2000.

Gasparini, G. P., Ortona, A., Budillon, G., Astraldi, M., and Sansone, E.: The effect of the Eastern Mediterranean Transient on the hydrographic characteristics in the Strait of Sicily and in the Tyrrhenian Sea, Deep-Sea Res. Pt. I, 52, 915-935, 2005.

Gleissberg, W. and Schove, D. J.: The eighty-year sunspot cycle, British Astronomical Association, 68, 148-152, 1958.

Gogou, A., Triantaphyllou, M., Xoplaki, E., Izdebski, A., Parinos, C., Dimiza, M., Bouloubassi, I., Luterbacher, J., Kouli, K., and Martrat, B.: Climate variability and socio-environmental changes in the northern Aegean (NE Mediterranean) during the last 1500 years, Quaternary Sci. Rev. 136, 209-228, 2016.

Gómez-Navarro, J. J., Montávez, J. P., Wagner, S., and Zorita, E.: A regional climate palaeosimulation for Europe in the period 1500-1990 - Part 1: Model validation, Clim. Past, 9, 1667-1682, https://doi.org/10.5194/cp-9-1667-2013, 2013.

Gómez-Navarro, J. J., Bothe, O., Wagner, S., Zorita, E., Werner, J. P., Luterbacher, J., Raible, C. C., and Montávez, J. P.: A regional climate palaeosimulation for Europe in the period 1500-1990 Part 2: Shortcomings and strengths of models and reconstructions, Clim. Past, 11, 1077-1095, https://doi.org/10.5194/cp-111077-2015, 2015.

Grauel, A.-L., Leider, A., Goudeau, M.-L. S., Müller, I. A., Bernasconi, S. M., Hinrichs, K.-U., de Lange, G. J., Zonneveld, K. A. F., and Versteegh, G. J. M.: What do SST proxies really tell us? A high-resolution multiproxy $\left(U_{37}^{\mathrm{K}^{\prime}}, \mathrm{TEXH}_{86}\right.$ and foraminifera $\delta 180$ ) study in the Gulf of Taranto, central Mediterranean Sea, Quaternary Sci. Rev., 73, 115-131, 2013.

Hammer, Ø., Harper, D. A., and Ryan, P. D.: PAST: Paleontological statistics software package for education and data analysis, Palaeontol. Electron., 4, 4, available at: http://palaeo-electronica. org/2001_1/past/issue1_01.htm (last access: 19 July 2021), 2001.

Herrmann, M., Sevault, F., Beuvier, J., and Somot, S.: What induced the exceptional 2005 convection event in the northwestern Mediterranean basin? Answers from a modeling study, J. Geophys. Res.-Ocean, 115, C12051, https://doi.org/10.1029/2010JC006162, 2010.

Incarbona, A., Martrat, B., Mortyn, P. G., Sprovieri, M., Ziveri, P., Gogou, A., Jordà, G., Xoplaki, E., Luterbacher, J., and Langone, 
L.: Mediterranean circulation perturbations over the last five centuries: Relevance to past Eastern Mediterranean Transient-type events, Sci. Rep. 6, 29623, https://doi.org/10.1038/srep29623, 2016.

Jianping, L. and Wang, J. X.: A new North Atlantic Oscillation index and its variability, Adv. Atmos. Sci., 20, 661-676, 2013.

Josey, S. A.: Changes in the heat and freshwater forcing of the eastern Mediterranean and their influence on deep water formation, J. Geophys. Res.-Oceans, 108, 3237, https://doi.org/10.1029/2003JC001778, 2003.

Josey, S. A., Kent, E. C., and Taylor, P. K.: New insights into the ocean heat budget closure problem from analysis of the SOC airsea flux climatology, J. Climate, 12, 2856-2880, 1999.

Josey, S. A., Somot, S., and Tsimplis, M.: Impacts of atmospheric modes of variability on Mediterranean Sea surface heat exchange, J. Geophys. Res.-Oceans, 116, C02032, https://doi.org/10.1029/2010JC006685, 2011.

Malanotte-Rizzoli, P., Artale, V., Borzelli-Eusebi, G. L., Brenner, S., Crise, A., Gacic, M., Kress, N., Marullo, S., Ribera d'Alcalà, M., Sofianos, S., Tanhua, T., Theocharis, A., Alvarez, M., Ashkenazy, Y., Bergamasco, A., Cardin, V., Carniel, S., Civitarese, G., D’Ortenzio, F., Font, J., Garcia-Ladona, E., Garcia-Lafuente, J. M., Gogou, A., Gregoire, M., Hainbucher, D., Kontoyannis, H., Kovacevic, V., Kraskapoulou, E., Kroskos, G., Incarbona, A., Mazzocchi, M. G., Orlic, M., Ozsoy, E., Pascual, A., Poulain, P.-M., Roether, W., Rubino, A., Schroeder, K., Siokou-Frangou, J., Souvermezoglou, E., Sprovieri, M., Tintoré, J., and Triantafyllou, G.: Physical forcing and physical/biochemical variability of the Mediterranean Sea: a review of unresolved issues and directions for future research, Ocean Sci., 10, 281-322, https://doi.org/10.5194/os-10-281-2014, 2014.

Millot, C.: Circulation in the Western Mediterranean Sea, J. Marine Syst., 20, 423-442, 1999.

Moreno, A., Pérez, A., Frigola, J., Nieto-Moreno, V., RodrigoGámiz, M., Martrat, B., González-Sampériz, P., Morellón, M., Martín-Puertas, C., and Corella, J. P.: The Medieval Climate Anomaly in the Iberian Peninsula reconstructed from marine and lake records, Quaternary Sci. Rev., 43, 16-32, 2012.

Neftel, A., Oeschger, H., and Suess, H. E.: Secular non-random variations of cosmogenic carbon-14 in the terrestrial atmosphere, Earth Planet. Sci. Lett., 56, 127-147, 1981.

Nieto-Moreno, V., Martínez-Ruiz, F., Willmott, V., García-Orellana, J., Masqué, P., and Damsté, J. S. S.: Climate conditions in the westernmost Mediterranean over the last two millennia: An integrated biomarker approach, Org. Geochem., 55, 1-10, https://doi.org/10.1016/j.orggeochem.2012.11.001, 2013.
Patterson, R. T., Prokoph, A., and Chang, A.: Late Holocene sedimentary response to solar and cosmic ray activity influenced climate variability in the NE Pacific, Sediment. Geol., 172, 67-84, 2004.

Patterson, R. T., Prokoph, A., Kumar, A., Chang, A. S., and Roe, H. M.: Late Holocene variability in pelagic fish scales and dinoflagellate cysts along the west coast of Vancouver Island, NE Pacific Ocean, Mar. Micropaleontol., 55, 183-204, 2005.

Roether, W., Manca, B. B., Klein, B., Bregant, D., Georgopoulos, D., Beitzel, V., Kovačević, V., and Luchetta, A.: Recent changes in eastern Mediterranean deep waters, Science, 80, 271, 333335, 1996.

Rohling, E. J., Marino, G., Grant, K. M., Mayewski, P. A., and Weninger, B.: A model for archaeologically relevant Holocene climate impacts in the Aegean-Levantine region (easternmost Mediterranean), Quaternary Sci. Rev., 208, 38-53, https://doi.org/10.1016/j.quascirev.2019.02.009, 2019.

Sicre, M.-A., Jalali, B., Martrat, B., Schmidt, S., Bassetti, M.-A., and Kallel, N.: Sea surface temperature variability in the North Western Mediterranean Sea (Gulf of Lion) during the Common Era, Earth Planet. Sci. Lett., 456, 124-133, 2016.

Sonett, C. P.: Very long solar periods and the radiocarbon record, Rev. Geophys. Sp. Phys., 22, 239-254, 1984.

Stuiver, M. and Braziunas, T. F.: Sun, ocean, climate and atmospheric ${ }^{14} \mathrm{CO}_{2}$ : An evaluation of causal and spectral relationships, Holocene, 3, 289-305, 1993.

Sur, H. I., Ozsoy, E., and Unluata, U.: Simultaneous deep and intermediate depth convection in the northern Levantine Sea, winter 1992, Oceanol. Acta, 16, 33-43, 1993.

Touratier, F. and Goyet, C.: Impact of the Eastern Mediterranean Transient on the distribution of anthropogenic $\mathrm{CO}_{2}$ and first estimate of acidification for the Mediterranean Sea, Deep-Sea Res. Pt. I, 58, 1-15, https://doi.org/10.1016/j.dsr.2010.10.002, 2011.

Versteegh, G. J. M., De Leeuw, J. W., Taricco, C., and Romero, A.: Temperature and productivity influences on $U_{37}^{\mathrm{K} \prime}$ and their possible relation to solar forcing of the Mediterranean winter, Geochem. Geophy. Geosy., 8, Q09005, https://doi.org/10.1029/2006GC001543, 2007.

Wüst, G.: On the vertical circulation of the Mediterranean Sea, J. Geophys. Res., 66, 3261-3271, https://doi.org/10.1029/JZ066i010p03261, 1961.

Zorita, E., González-Rouco, F., and Legutke, S.: Testing the approach to paleoclimate reconstructions in the context of a 1000Yr control simulation with the ECHO-G coupled climate model, J. Climate, 16, 1378-1390, 2003 